\title{
Long term management of obstructive sleep apnea and its comorbidities
}

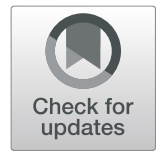

Marta Marin-Oto ${ }^{1}$, Eugenio E. Vicente ${ }^{2,4}$ and Jose M. Marin $3,4^{*}$

\begin{abstract}
Obstructive sleep apnea (OSA) is a worldwide highly prevalent disease associated with systemic consequences, including excessive sleepiness, impairment of neurocognitive function and daytime performance, including driving ability. The long-term sequelae of OSA include and increase risk for cardiovascular, cerebrovascular and metabolic syndrome disorders that ultimately lead to premature death if untreated. To ensure optimal long-term outcomes, the assessment and management of OSA should be personalized with the involvement of the appropriate specialist. Most studies have demonstrated inmediate improvement in daytime somnolence and quality of life with CPAP and other therapies, but the effect of long-term treatment on mortality is still under debate. Currently, the long-term management of OSA should be based on a) identifying physiological or structural abnormalities that are treatable at the time of patient evaluation and b) comprehensive lifestyle interventions, especially weight-loss interventions, which are associated with improvements in OSA severity, cardiometabolic comorbidities, and quality of life. In long-term management, attention should be paid to the clinical changes related to a potential reoccurrence of OSA symptoms and it is also necessary to monitor throughout the follow up how the main associated comorbidities evolve.
\end{abstract}

Keywords: Obstructive sleep apnea, Cardiovascular disease, Hypertension, Diabetes, Dislipemia, Long-term management, Outcomes

\section{Introduction}

We define obstructive sleep apnea (OSA) as an entity characterized by repeated collapses of the pharynx during sleep that reduce or eliminate airflow completely for at least $10 \mathrm{~s}$ and in a number of 5 episodes or more every hour of sleep (Apnea-Hipopnea Index, -AHI-). These episodes are associated with sympathetic activation, exaggerated negative swings in intrathoracic pressure, intermittent oxyhemoglobin desaturation, hypercapnia and arousal from sleep. These physiological changes seem to act as intermediate mechanisms responsible for the accelerated development of new comorbidities. This topic has been reviewed extensively in Multidisciplinary Respiratory Medicine by MR Bonsignore et al. [1]. In this chapter we will review three relevant questions: 1) the available information on the natural history of OSA and its relationship with incident comorbidities,

\footnotetext{
*Correspondence: jmmarint@unizar.es

${ }^{3}$ Respiratory Service, Hospital Universitario Miguel Servet, and Department of Medicine, University of Zaragoza, Avda. Isabel la Católica, 1-3, 50009

Zaragoza, Spain

${ }^{4}$ Traslational Respiratory Research Unit, IISAragon, Zaragoza and CIBER

Enfermedades Respiratorias, Instituto Salud Carlos III, Madrid, Spain Full list of author information is available at the end of the article
}

particularly cardiovascular ones, 2) how the available treatment for patients with OSA does impact the evolution of OSA and 3) how the OSA treatment can modify the health outcomes of the comorbidities associated with OSA. Unfortunately, there is little information in the literature on both subjects. This is so, because since the appearance of continuous positive airway pressure (CPAP) as an effective treatment to reverse OSA symptomatology, it would not be ethical to study the natural history of symptomatic patients with OSA for a long time of period without offering them an effective treatment.

\section{Clinical course of obstructive sleep apnea}

OSA is actually part of a "continuous" patho-physiological process in which the upper airway (UA), mainly the pharynx, shows a high resistance to air flows (Fig. 1). Initially this dysfunction is asymptomatic or manifested by snoring: "stage of susceptibility". Predisposed subjects probably have a genetic load of susceptibility that we are largely unaware of. With adulthood and in parallel with weight gain, environmental and epigenetic factors aggravate the collapsibility of the UA. In this "pre-symptomatic" stage,

(c) The Author(s). 2019 Open Access This article is distributed under the terms of the Creative Commons Attribution 4.0 International License (http://creativecommons.org/licenses/by/4.0/), which permits unrestricted use, distribution, and 


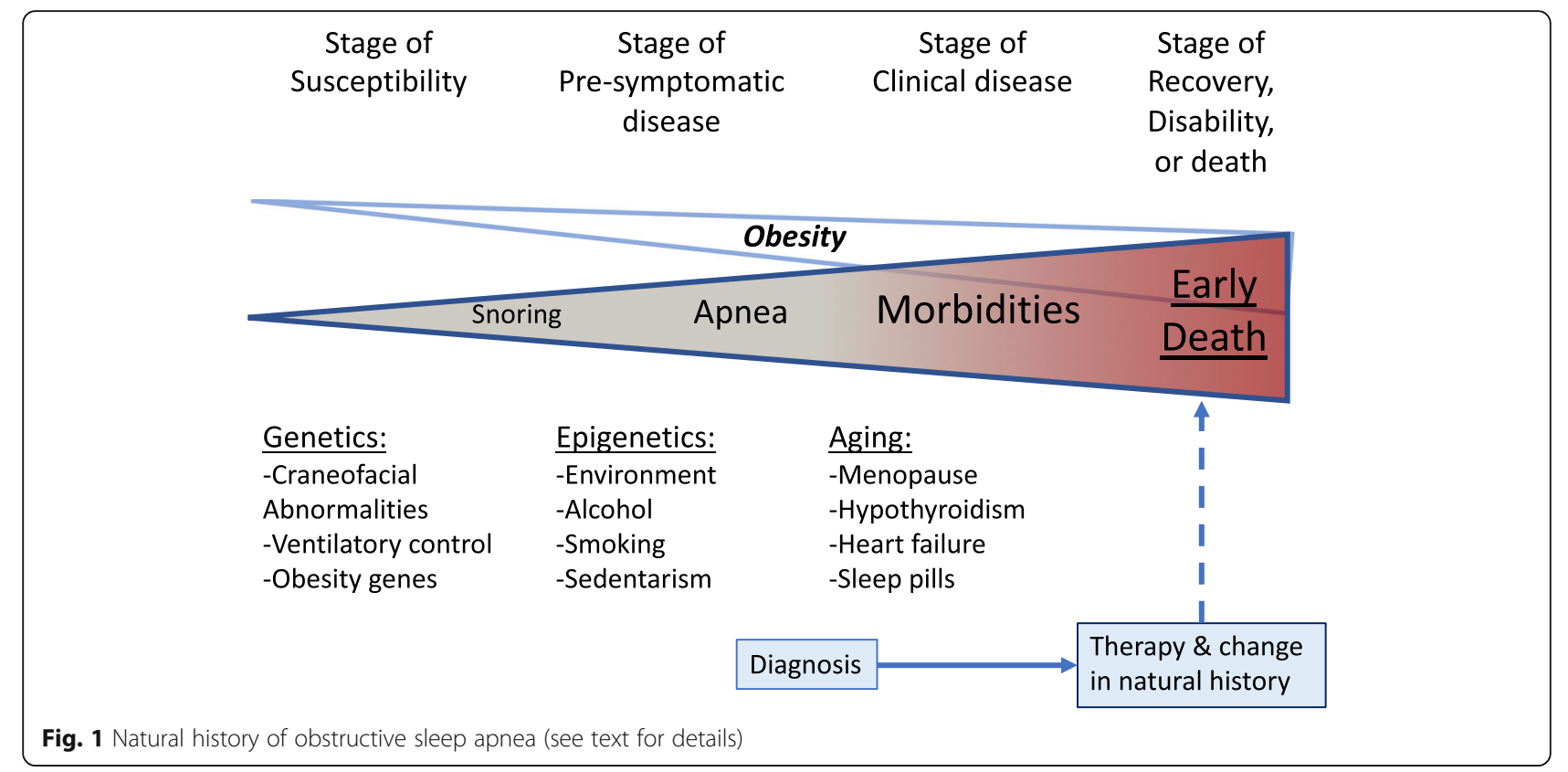

snoring is usually aggravated, nocturnal apneas appear but the subject may not report a diurnal limitation in his/her activities. Without solution of continuity, the patient evolves towards a "stage of clinical illness" in which morbidities develop at younger ages with respect to the non-OSA population in what we could consider in some way an accelerated aging. If patients are not identified and treated, the natural evolution is towards disability and premature death mainly due to cardiovascular events.

In current medicine, knowledge about the natural evolution of diseases is based on the descriptions made by doctors in the last century. It is not possible with current treatments to validate these descriptions through observational cohort studies and much less with randomized controlled trials (RCT). In OSA it happens the same thing. The first detailed descriptions of OSA were made by European authors. However, these reports did not describe the long-term evolution of the disease [2,3]. Before the description by Sullivan et al of the efficacy of CPAP for the treatment of OSA [4], physicians who treated these patients only had upper airway surgery (including tracheotomy). Early clinical descriptions of OSA included substantial disability and health care utilization, largely reflecting the limited management options available at the time. Many patients evolved towards the development of heart failure and respiratory failure or dying in various accidents. The majority of these patients were young adults. In the last 30 years, many studies on the evolution and short- and long-term management of OSA have been published. We review here briefly the most significant studies grouping them according to their study design: clinical based cohort, community-based cohort and RCT (Table 1).

\section{Cohort studies}

The first clinical-based and retrospective studies seemed to indicate that patients with severe OSA treated with tracheotomy and CPAP had better survival than those treated with uvulo-palato-pharyngoplasty (UPPP) or by conservative measures [5, 6]. Mortality rates were around 6\% per 5-8 years among the untreated patients, being cardiovascular events the most frequents causes of death. What was interesting about these early studies is that, despite their methodological limitations, it appears that the "complete" suppression of apneas/hypopneas with treatments such as tracheotomy or CPAP could improve the survival of patients with OSA, while other "partial" efficacy techniques (e.g. the UPPP) did not influence the health outcomes of the patients, therefore cannot be recommended to treat the most severe cases of OSA. There were another four prospective studies with three of them only including elderly population with contradictory results [7-10]. All six studies had many methodologic limitations because they failed adequately to take into account important confounding risk factors for cardiovascular diseases, such as obesity, smoking, dyslipemia, or hypertension. As stated in a systematic review published in 1997 by Wright et al., the results of those studies showed inconsistent results with limited evidence to link OSA with an excess of mortality [11]. 
Table 1 Long-term mortality studies in obstructive sleep apnea

\begin{tabular}{|c|c|c|c|c|c|}
\hline $1^{\text {st }}$ autor, and reference & Design & Sample & $\begin{array}{l}\text { Mean } \\
\text { Age }\end{array}$ & $\begin{array}{l}\text { Mean follow } \\
\text { up }\end{array}$ & Results \\
\hline \multicolumn{6}{|c|}{ Cohort studies published before 1996} \\
\hline He et al.; (Ref. \#5) & Retrospective & 385 & 52 & N. A & $\begin{array}{l}\text { Al }>20 \text { has a RR mortality of } 1.5 \text { vs } \mathrm{Al}<20 \text { UPPP vs conservative: no } \\
\text { differences }\end{array}$ \\
\hline Partinen et al.; (Ref. \#6) & Retrospective & 198 & 56 & 5 years & Tracheostomy vs conservative 5 years survival: $0 \%$ vs $6 \%$ \\
\hline Bliwise et al.; (Ref. \#7) & Prospective & 298 & 69 & Up 12 years & RR mortality for RDI > 10 of $2.67(0.95-7.5,95 \% \mathrm{Cl})$. \\
\hline $\begin{array}{l}\text { Ancoli-Israel et al.; (Ref. } \\
\# 8 \text { ) }\end{array}$ & Prospective & 233 & 83 & 3.3 years & Significant association of AHI with death in women but not in men \\
\hline Mant et al.; (Ref. \#9) & Prospective & 163 & 83 & 4 years & No relationship between RDI and survival \\
\hline Lavie et al.; (Ref. \#10) & Prospective & 1620 & 48 & 12 years & Mortality OR of 1.012 for $\mathrm{Al}>10$ (not significant) \\
\hline \multicolumn{6}{|c|}{ Cohort studies published after 1996} \\
\hline Lavie et al.; (Ref. \#12) & Prospective & 13,850 & 48 & 4.5 years & HR all-cause mortality, 2.2 for RDI > 30 (significant) \\
\hline Yaggi et al. (Ref.\#13) & Prospective & 1022 & 61 & 3.4 years & HR all-cause mortality, 3.3 for AHI > 36 (significant) \\
\hline Marin et al.; (Ref. \# 14) & Prospective & 1651 & 50 & 10 years & OR cardiovascular mortality, 2.87 for AHI > 30 (significant) \\
\hline Young et al.; (Ref. \#15) & Prospective & 1522 & 48 & 18 years & HR all-cause mortality, 3.8 for AHI > 30 (significant) \\
\hline Marshall et al.;(Ref. \#16) & Prospective & 400 & 53 & 20 years & HR all-cause mortality, 4.2 for RDI > 15 (significant) \\
\hline Punjabi et al.; (Ref.\#17) & Prospective & 6441 & 63 & 10 years & HR all-cause mortality, 2.09 for $\mathrm{AHI}>30$ (in men aged $40-70$ years) \\
\hline
\end{tabular}

Abbreviations: $A$ l apnea index $R R$ risk ratio, UPPP uvulopalatopharyngoplasty, $A H I$ apnea-hipopnea index, $R D I$ respiratory disturbance index, $O D$ odds ratio, $H R$ hazard ratio, CVS cardiovascular, OSA obstructive sleep apnea

Since the Wright's paper was published, many well designed longitudinal studies have confirmed increased mortality in OSA patients. In Israel, Lavie and colleagues collected mortality information among a very large cohort of 14,589 men referred to the sleep clinics with suspected sleep apnea [12]. After a median follow up of 4.6 years, Cox proportional analysis revealed that both BMI and RDI were independently associated with mortality. Unfortunately, no other potential risk of mortality, clinical status at diagnosis, or therapy was controlled. In USA, among patients without pre-existing cardiovascular diseases who were referred to a Sleep Center for the evaluation of sleep-disordered breathing, Yaggi and colleagues reported an increased risk for death or stroke in OSA patients and a dose-effect relationship between OSA severity and risk [13]. Unfortunately, use of nasal CPAP was not evaluated and the short duration of follow up (3 years) and the small number of observed events did not allow the specific assessment of the effects of therapy. In 2005, we reported the long-term cardiovascular outcomes in men with OSA referred to our sleep unit between January 1, 1992, and December 31, 1994 [14]. During the recruitment period, 1,465 patients had polysomnography and treatment with CPAP was recommended to 667 patients. Patients attended the clinic yearly. During these visits, compliance with CPAP therapy was assessed by the timer built into each CPAP device. A mean daily use of more than $4 \mathrm{~h}$ per day was considered necessary to maintain the CPAP prescription. After a mean of 10.1 years, Patients with untreated severe OSA had a higher incidence rate of fatal events
(1.06 events per 100 person-years) than untreated patients with mild-moderate OSA (0.55 events, <0.02); simple snorers $(0.34$ events, $p<.0005)$; patients treated with nasal CPAP $(0.35$ events, $p<.005)$; and healthy subjects $(0.3$ events, $p<.005)$. Multivariate analysis adjusted for potential confounders showed that untreated severe OSA increased significantly the risk of fatal cardiovascular events (odds ratio 2.87; 95\% CI, 1.17-7.51) compared with healthy subjects (Table 2). At the time, this study was very relevant because it contributed not only to the knowledge of the natural history of OSA, but also to establish $\mathrm{AHI}>30$ as a defining reference value for severe OSA. It was also the first paper to report that CPAP therapy reduces the risk of fatal and non-fatal cardiovascular outcomes in OSA.

Some population studies have confirmed the results of these clinical-based cohort studies. In a 18-year mortality follow up conducted on the Wisconsin Sleep Cohort sample $(n=1522)$, the adjusted hazard ratio $(95 \% \mathrm{CI})$ for all-cause mortality with severe OSA (AHI > 30) versus no OSA was $3.8(1.6,9.0)$ irrespective of symptoms of sleepiness [15]. The Busselton study confirms this finding in a relatively young population in Australia [16], while in a somewhat older population such as Sleep Health Heart Study, the excess mortality associated with OSA was only shown in men [17]. The problem with these three epidemiological studies is that the effect of OSA treatment on health outcomes could not be adequately evaluated.

In addition with mortality, in cohort studies, OSA has been linked with incident cardiovascular outcomes such as hypertension [18], coronary artery disease [19], 
Table 2 Fully adjusted odds ratio for cardiovascular death associated to clinical variables and diagnosis status

\begin{tabular}{lll}
\hline Variable & $\begin{array}{l}\text { Odds Ratio (95\% Confidence } \\
\text { Interval) }\end{array}$ & $P$ \\
\hline Age, years & $1.09(1.04-1.12)$ & 0.001 \\
$\begin{array}{l}\text { Diagnostic group } \\
\quad \text { Snoring (AHI<5) }\end{array}$ & $1.03(0.31-1.84)$ & 0.88 \\
$\begin{array}{l}\text { Mild-moderate OSA (AHI: 5- } \\
\text { 15) }\end{array}$ & $1.15(0.34-2.69)$ & 0.71 \\
$\begin{array}{l}\text { Severe untreated OSA (AHI: } \\
\text { 15-30) }\end{array}$ & $2.87(1.17-7.51)$ & 0.025 \\
$\begin{array}{l}\text { OSA treated with CPAP (AHI: } \\
>\text { 15) }\end{array}$ & $1.05(0.39-2.21)$ & 0.74 \\
Prevalent CVS disease & $2.54(1.31-4.99)$ & 0.005 \\
\hline
\end{tabular}

Abbreviations: CPAP continuous positive airway pressure, CVS cardiovascular, OSA obstructive sleep apnea, $A H I$ apnea-hipopnea index. Adapted from Marin $\mathrm{JM}$, et al. (reference \# 14)

myocardial infarction [20] and stroke [13]. Given the increased cardiovascular morbidity and mortality in patients with OSA, the possibility that OSA was also a risk factor for developing other cardiovascular risk factors such as diabetes or dyslipidemia, has been investigated in these cohort studies. A recent meta-analysis that includes a total of 64,101 participants reveals that OSA is associated with incident diabetes, with an unadjusted pooled relative risk of 1.62 (95\% CI, 1.45-1.80) [21]. There are, however, no reports that have specifically explored the development of dyslipidemia in longitudinal studies. Patients with OSA commonly experience memory problems, and neurocognitive disfunction [22], however, there are no data that allow associating OSA and incident dementia. As part of the cognitive disfunction and daytime sleepiness, it is well known that patients with OSA are at higher risk for motor vehicle accidents [23]. Finally, excess mortality in patients with OSA could also be justified by an increased incidence of all types of malignancies, especially in young adults with severe OSA $[24,25]$.

\section{Randomized studies}

Long-term randomized controlled trials (RCTs) with the aim of evaluating the effect of treatment on morbidity and mortality in OSA are difficult to carry out due to the insurmountable ethical problems that supposed to stop treating patients with significant diurnal symptoms. However, some RCTs have been carried out to assess the effect of treatment on diurnal symptoms and quality of life during relatively short time. Most studies have evaluated the effect of CPAP on excessive daytime sleepiness (EDS) [26, 27] and health status [27]. Additionally, these studies immediately showed that the positive effects of CPAP required a minimum effective use of more than $4 \mathrm{~h}$ a day.
As an alternative for patients intolerant to CPAP, mandibular advancement oral appliance therapy (MAT) can be considered. Some short-term (3 months) RCT have shown similar improvement in somnolence, vigilance, and neurocognitive performance with MAT, compared with CPAP in patients with mild-to-moderate OSA [28]. Upper airway surgery as a treatment option for OSA has been extensively reviewed and meta-analyzed [29], however, until now, RCTs that have demonstrated their efficacy on the symptomatology and quality of life of patients with OSA have not been carried out.

Weight-loss intervention is effective to improve the cardiovascular risk-factor profile in obese patients with or without OSA. In addition, all bariatric surgery procedures achieve improvement in their sleep apnea however, OSA can persist in after substantial weight loss [30] so follow up sleep study needs to be done to determine whether further OSA therapy is needed despite weight loss. In RCT, the combined therapy of CPAP with weight-loss intervention resulted in a larger reduction in blood pressure than either CPAP or weight loss alone [31]. There are no RCT head to head studies to compare the effect of bariatric surgery versus CPAP, MAT or other therapies.

\section{Role of OSA in the evolution of other comorbid diseases}

Given that the majority of patients with OSA present some comorbidity, especially cardiovascular or metabolic, it is relevant to know how the most prevalent and relevant comorbidities, mainly cardiovascular risk factors, will evolve depending on the treatment applied to control apneas.

\section{Hypertension}

Arterial hypertension in patients with OSA should be treated according to the current guidelines regardless of the specific treatment that is to be applied for sleep apnea. Nevertheless, three circumstances must be considered in the relationship hypertension - OSA.

A) In the normotensive patient with OSA who consults for the first time, what is the future risk of developing hypertension? Put it in another way, is the treatment of OSA effective for the primary prevention of hypertension? There are data that suggest it. After considering confounding factors, the odds of developing incident hypertension over 4 years in non-hypertensive OSA patients that received no treatment, was threefold greater for those with an AHI $>15$ at baseline in population studies [32], and twofold in clinical studies [33, 34] compared with participants without OSA. However, in the latter study, compared with controls, the 
adjusted HRs for incident hypertension were greater among patients with OSA ineligible for CPAP therapy $(1.33$; 95\% CI, 1.01-1.75), among those who declined CPAP therapy (1.96; 95\% CI, 1.44-2.66), and among those nonadherent to CPAP therapy (1.78; 95\% CI, 1.23-2.58), whereas the HR was lower in patients with OSA who were treated with CPAP therapy $(0.71 ; 95 \%$ CI, 0.53-0.94) [33]. These results were confirmed in a post hoc analysis of a RCT performed during 4 years with normotensive patients with OSA and without excessive daytime sleepiness. In this multicentric study, CPAP treatment reduce the incidence of hypertension or cardiovascular events in patients with CPAP adherence of $4 \mathrm{~h} /$ night or longer [35].

B) In patients with OSAS and associated hypertension, how do the blood pressure (BP) figures in treated and untreated subjects behave? This has been one of the most studied topics of sleep medicine related to OSA. From several recent RCTs and meta-analyzes, it can be concluded that: in patients treated with CPAP that show good compliance, diurnal systolic and diastolic $\mathrm{BP}$ are reduced by an average of $-2.58 \mathrm{mmHg}(95 \%$ $\mathrm{CI},-3.57$ to $-1.59 \mathrm{mmHg})$ and -2.01 (95\% CI, 2.84 to $-1.18 \mathrm{mmHg}$ ) compared to patients with untreated OSA. The effects were stronger in younger and sleepier patients and more severe OSA [36]. It should always be borne in mind that the reduction of $\mathrm{BP}$ is a collateral effect of CPAP and that, this treatment should not be used with the specific objective of reducing the BP Figs.

C) In a patient with arterial hypertension, when should the co-existence of OSA and its potential role in the pathogenesis of hypertension be suspected? Since more than $80 \%$ of OSA patients have a nondipping BP profiles in a sample of untreated patients with mild to severe OSA [37], hypertensive subjects that demonstrate a BP drop $<10 \%$ of daytime values (non-dippers) during a $24 \mathrm{~h}$ ambulatory blood pressure monitoring (ABPM), should have a sleep study to rule out OSA. These hypertensive non-dippers are at higher risk of incident cardiovascular events, and increased risk of renal disease progression as compared to nocturnal dippers [38]. Another very important group of hypertensive patients in whom a sleep study is needed to rule out the coexistence of OSA are those with resistant hypertension $(\mathrm{RH})$ defined as an office $\mathrm{BP} \geq 140 / 90$ $\mathrm{mmHg}$ despite the use of 3 or more antihypertensive agents [39]. In this subgroup, the prevalence of OSA is reported to be 70-83\% [40] and the treatment with CPAP showed a favorable reduction of $\mathrm{BP}$ in RCT [41]. In summary, since among hypertensive patients there was a dose-dependent reduction in blood pressure and incident cardiovascular diseases [42], those patients with comorbid OSA who receive effective treatment with CPAP are also receiving a treatment that helps them stabilize their blood pressure and reduce their cardiovascular morbidity and mortality.

\section{Diabetes}

It is recognized that the prevalence of diabetes among patients with OSA is greater than that in the non-OSA population, and exhaustive reviews of the relationship between OSA and diabetes have recently been published [43]. On the other hand, based on clinical and population-based observational cohort studies, patients with severe OSA (eg AHI > 30), without initial diabetes mellitus (DM), are considered to have an increased risk of developing DM in the future. $[44,45]$. There is no information on the role played by the long-term treatment of OSA in reducing or not the risk of developing diabetes.

Conversely, in observational studies of diabetic subjects with OSA, effective treatment of OSA tend to improve indicators of glycemic status [46]. A recent systematic review and meta-analysis concluded that CPAP does not improve glycemic control measure as HbA1c [47]. However, the studies reviewed included mostly non-sleepy patients, were of short duration (12 to 24 weeks) and in most of them, the daily use of CPAP was lower than $4 \mathrm{~h}$. Again, the selection of patients with OSA that are included in the RCTs, is in itself a bias that does not reflect the reality of the patients we see in the clinics on a daily basis. For example, it is known that the effect of CPAP on glucose metabolism is more effective when patients are drowsier [48]. The clinician must manage their diabetic patients with OSA based on the clinical guidelines and should focus primarily on weight reduction. as a target treatment for both the management of diabetes and OSA.

\section{Dyslipidemia}

Several observational studies [49] and a meta-regression analysis [50] support the existence of a link between OSA and dyslipidemia. No studies have been conducted to establish whether the treatment or not of OSA is associated with a reduction in the risk of developing dyslipidemia in subjects without lipid alterations at baseline. On the other hand, there are RCTs that have evaluated the response of CPAP in terms of blood lipids in patients with OSA and dyslipidemia with mixed results $[51,52]$. Again, it should be emphasized that the results of the RCTs do not exactly reflect the usual patient attended at sleep clinics. For example, the improvement of hypersomnolence could be associated with increased physical activity and caloric output, which can also contribute towards improving dyslipidemia. Therefore, it is 
difficult to identify in the context of an integral management of the patient with OSA (e.g hygienic-dietetic measures, promotion of exercise, abstinence from tobacco and alcohol, CPAP, upper-airway surgery, etc. ...), which of the therapeutic measures on an individual basis is more effective to improve the lipid profile and health outcomes.

\section{Cardiovascular diseases}

The acute and chronic cardiovascular effects of sleep apnea are well known and have been extensively studied [53]. On the other hand, among patients with OSA, the prevalence of diseases promoted by atherosclerosis (eg, stroke, ischemic heart disease, aneurysms, etc.) is higher. The evidence of an increased risk of cardiovascular morbidity and mortality among patients with untreated OSA is consistent but comes from long-term clinical and population studies [14-17]. There are also epidemiological studies that have indicated a reduction in cardiovascular risk in patients with OSA treated correctly with CPAP or with tracheostomy [14, 54]. The development of RCT studies that confirm a causal relationship will not be possible for reasons indicated above. Based on this evidence and in parallel with how we inform our smokers, the doctor must communicate to their patient with severe OSA the risk and potential benefit of the treatment of their underlying disease.
Another different problem is the influence it has on the clinical course of an already established cardiovascular disease (eg coronary atherosclerotic disease, stroke, aneurysm), suffering from OSA as an associated morbidity. In the cardiovascular literature it is well established that treating, for example, hypertension or dyslipidemia of a patient with established coronary disease will ultimately reduce the likelihood of new cardiovascular events (secondary prevention). The effect of treating OSA in this type of patients is not so clear. RCTs done in patients recruited in cardiac clinics, mostly with already cardiovascular or cerebrovascular events, did not show an improving in morbi-mortality compared to those treated with CPAP. Nevertheless, a significant improvement was reported in daytime sleepiness, quality of life, mood, and work productivity in patients who received CPAP $[55,56]$. From the practical point of view and until we know the results of more RCT currently underway, we must act with patients with cardiovascular disease and suspected OSA, following the same strategy as with the "non-cardiovascular" patients. That is, based on a good sleep history, ordering the appropriate sleep study and designing the personalized treatment for each case based on the current guidelines. For our part, we would add that the sleep studies in this type of patients should always be "attended" to specify the dominant type of breathing-sleep disorder (eg, obstructive apneas, central apneas) and if positive pressure ventilation is

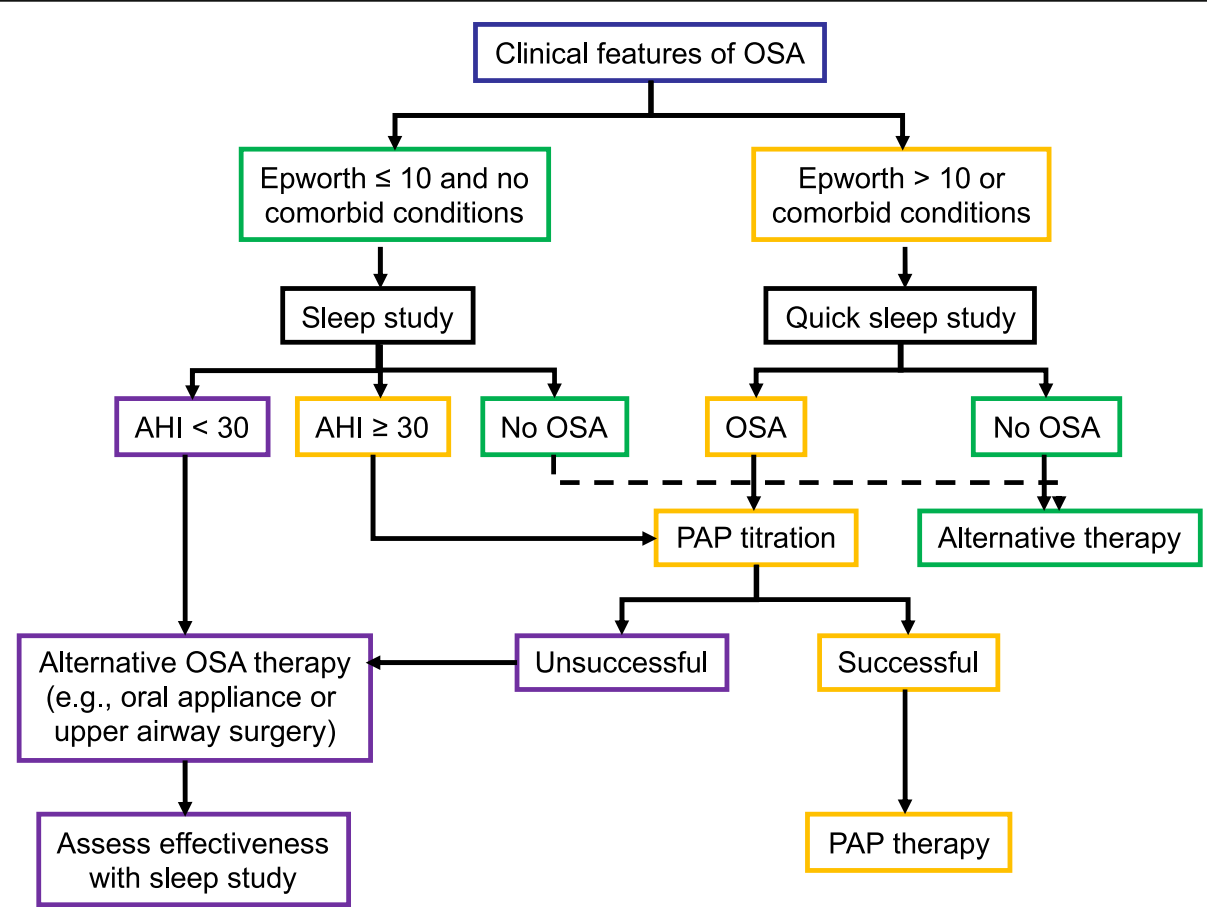

Fig. 2 Treatment algorithm for obstructive sleep apnea (OSA). This flow diagram shows a general approach to the management of patients with suspected OSA. See Box 61-2 for the Epworth Sleepiness Scale. AHI, apnea-hypopnea index; PAP, positive airway pressure 
Table 3 The 10 OSA Commandments ${ }^{\oplus}$

\begin{tabular}{|c|c|c|}
\hline Prevention & । & Help to avoid overweight and obesity \\
\hline \multirow[t]{5}{*}{ Diagnosis } & $\|$ & $\begin{array}{l}\text { Suspect OSA in cases of snoring and/or visualized } \\
\text { apneas or daytime sleepiness }\end{array}$ \\
\hline & III & Confirm the diagnosis. Perform sleep study \\
\hline & IV & Quantify sleepiness, BMI, AHI, and nocturnal hypoxemia \\
\hline & V & $\begin{array}{l}\text { Identified comorbidities, particularly cardiovascular, } \\
\text { metabolic and neurocognitive deficits }\end{array}$ \\
\hline & $\mathrm{Vl}$ & $\begin{array}{l}\text { Explore the upper airway and look for treatable } \\
\text { anatomic abnormalities }\end{array}$ \\
\hline \multirow[t]{3}{*}{ Treatment } & VII & Establishes a program to reduce weight \\
\hline & VIII & Start patient-specific treatment \\
\hline & IX & $\begin{array}{l}\text { Supervise the correct use of CPAP and other devices } \\
\text { and medications }\end{array}$ \\
\hline Follow-up & $x$ & $\begin{array}{l}\text { Establish a follow up plan and measure response to } \\
\text { treatment }\end{array}$ \\
\hline
\end{tabular}

Abbreviations: OSA obstructive sleep apnea, $B M I$ body mass index, $A H I$ apneahipopnea index, CPAP continuous positive airway pressure

Copyright $\odot$ 2016. Grupo BODE

required, its titration should always be done manually in a second sleep study.

\section{The present strategy in the long-term management of OSA}

There is no worldwide consensus about the management of OSA. Several scientific societies have clinical management guidelines for the initial treatment of OSA [5759]. Figure 2 shows our strategy for the prescription of CPAP. Currently sleep specialist are moving to treat their patients from a mechanistic perspective grouping patient into phenotypic traits that cause OSA such upper airway anatomic compromise, high loop gain, low respiratory arousal threshold and poor pharyngeal muscle responsiveness during sleep [60]. However, there is no specific recommendation on how the patient's long-term follow up process should be, what specialist should initiate the patient's diagnostic and therapeutic process, how often and until when a patient's course should be followed after being diagnosed or when should a new sleep study be carried out.

In addition to an intervention to increase the upper airway lumen with pharyngeal surgery or to prevent the collapsibility of the upper airway with the application of CPAP, the management of OSA should always include lifestyle intervention. A comprehensive lifestyle intervention (CLI) program includes a reduced-calorie diet, exercise/increased physical activity, and behavioral counseling. A seminal RCT of a CLI demonstrated significant improvement in AHI parallel with weightloss [61]. CLI is particularly effective in overweight and obese patients with OSA. A CLI program that effectively achieves a weight reduction, not only improves the AHI, but simultaneously impacts on the prognosis of a coexisting diabetes [62], hypertension and cardiovascular diseases [63]. A recent
Clinical Practice Guideline document from the American Thoracic Society summarizes the principles and recommendations of CLI in the management of OSA [64].

The current trend is that any recommendation included in the guidelines must be strictly evidence-based. However, in many real-world situations, evidence is not available. In our opinion, when irrefutable evidence is lacking on certain aspects of clinical management, common sense and good practices should prevail. Some recommendations in the field of sleep-breathing disorders should be implemented without the need for large randomized trials. Indeed, there is no randomized trial supporting the benefit of smoking cessation, yet it is recommended in all guidelines. One of the responsibilities of a physician is to interpret their patients' individual problems. We have brought in our Sleep Clinic the recommendations derived from scientific knowledge in the area of OSA, and, following the worthy example of a passage from the Old Testament that has served humanity for thousands of years, have set them down in 10 OSA commandments (Table 3). This simple guideline constitutes an attractive, easy and practical approach to the management of COPD in all its variations and will give physicians the freedom to provide the best possible care to their patients.

\section{Conclusions}

The current knowledge about the clinical course or natural history of the disease in the case of obstructive sleep apnea, comes largely from the clinical experience of the physicians who have handled this type of patients for decades. In support of this knowledge, we only have some clinical-base and populational observational studies. Unlike other areas of medicine, in the case of OSA, we will not be able to have large long-term RCTs that help us to define the management of our patients. At present, the initial treatment of patients with OSA should focus on eliminating apneas with personalized therapy for each subject with the ultimate goal of normalizing the quality of life and control or delay the occurrence of comorbidities. To help achieve this goal, we must include the patient in lifestyle improvement programs with the ultimate goal of reducing weight and increasing physical activity, especially in overweight or obese subjects.

\footnotetext{
Abbreviations

ABPM: Ambulatory blood pressure monitoring; AHI: Apnea hypopnea index; BMI: Body mass index; BP: Blood pressure; CPAP: Continuous positive airway pressure; DM: Diabetes mellitus; MAT: Oral appliance therapy; OSA: Obstructive sleep apnea; RCT: Randomized controlled trial; RDI: Respiratory disturbance index; RG: Resistant hypertension; UA: Upper airways; UPPP: Uvulopalatopharyngoplasty
} 


\section{Funding}

This work has been funded by Instituto Salud Carlos III (PI18/01524), Ministerio de Ciencia, Innovación y Universidades, Madrid, Spain. The funding bodies had no role in the design of the study and collection, analysis, and interpretation of data and in writing the manuscript.

\section{Availability of data and materials}

Not applicable.

\section{Authors' contributions}

JMM conceived the manuscript; MM-O, EEV and JMM, contributed to design the manuscript and reference search; all authors contributed in writing the manuscript. All authors read and approved the final manuscript.

\section{Ethics approval and consent to participate}

Not applicable.

\section{Consent for publication}

Not applicable.

\section{Competing interests}

The authors declare that they have no competing interest. JMM is a member of the Editorial Board of Multidisciplinary Respiratory Medicine.

\section{Publisher's Note}

Springer Nature remains neutral with regard to jurisdictional claims in published maps and institutional affiliations.

\section{Author details}

${ }^{1}$ Department of Respiratory Medicine, Clinica Universitaria de Navarra, University of Navarra, Pamplona, Spain. ${ }^{2}$ Otorhinolaryngology Service, Hospital Universitario Miguel Servet, Zaragoza, Spain. ${ }^{3}$ Respiratory Service, Hospital Universitario Miguel Servet, and Department of Medicine, University of Zaragoza, Avda. Isabel la Católica, 1-3, 50009 Zaragoza, Spain. ${ }^{4}$ Traslational Respiratory Research Unit, IISAragon, Zaragoza and CIBER Enfermedades Respiratorias, Instituto Salud Carlos III, Madrid, Spain.

\section{Received: 20 March 2019 Accepted: 8 May 2019}

\section{Published online: 04 July 2019}

\section{References}

1. Bonsignore MR, Baiamonte P, Mazzuca E, Castrogiovanni A. Obstructive sleep apnea and comorbidities: a dangerous liaison. Multidiscip Respir Med. 2019:14:8. https://doi.org/10.1186/s40248-019-0172-9.

2. Gastaut H, Tassinari C, Duron B. Etude polygraphique des manifestations episodiques (hypniques et respiratoires) du syndrome de Pickwick. Rev Neurol. 1965;112:568-79.

3. Lugaresi E, Coccagna G, Mantovani M. Hypersomnia with periodic apneas In: Advances in Sleep Research, Volume 4, E. Weitzman (Ed.). New York: Spectrum Publications; 1978. p. 68-70.

4. Sullivan CE, Issa FG, Berthon-Jones M, Eves L. Reversal of obstructive sleep apnoea by continuous positive airway pressure applied through the nares. Lancet. 1981;1(8225):862-5.

5. He J, Kryger MH, Zorick FJ, Conway W, Roth T. Mortality and apnea index in obstructive sleep apnea. Experience in 385 male patients. Chest. 1988;94(1):9-14.

6. Partinen M, Jamieson A, Guilleminault C. Long-term outcome for obstructive sleep apnea syndrome patients. Mortality. Chest. 1988; 94(6):1200-4

7. Bliwise DL, Bliwise NG, Partinen M, Pursley AM, Dement WC. Sleep apnea and mortality in an aged cohort. Am J Public Health. 1988;78:544-7.

8. Ancoli-Israel S, Kripke DF, Klauber MR, Fell R, Stepnowsky C, Estline E, et al: Morbidity, mortality and sleep-disordered breathing in community dwelling elderly. Sleep. 1996;19:277-82.

9. Mant A, King M, Saunders NA, Pond CD, Goode E, Hewitt H. Four-year follow-up of mortality and sleep related respiratory disturbance in nondemented seniors. Sleep. 1995:18:433-8.

10. Lavie P, Hever P, Peled R, Berger I, Yoffe N, Zomer J, Rubin AH. Mortality in sleep apnea patients: a multivariate analysis of risk factors. Sleep. 1995;18:149-57.
11. Wright J, Johns R, Watt I, Melville A, Sheldon T. Health effects of obstructive sleep apnoea and the effectiveness of continuous positive airways pressure: a systematic review of the research evidence. BMJ. 1997;314:851-60.

12. Lavie $P$, Lavie $L$, Herer P. All-cause mortality in males with sleep apnoea syndrome: declining mortality rates with age. Eur Respir J. 2005;25:514-20.

13. Yaggi HK, Concato J, Kernan WN, Lichtman JH, Brass LM, Mohsenin V. Obstructive sleep apnea as a risk factor for stroke and death. N Engl J Med. 2005;353:2034-41.

14. Marin JM, Carrizo SJ, Vicente E, Agusti A. Long-term cardiovascular outcomes in men with obstructive sleep apnoea-hypopnoea with or without treatment with continuous positive airway pressure: an observational study. Lancet. 2005;365:1046-53.

15. Young T, Finn L, Peppard PE, Szklo-Coxe M, Austin D, Nieto FJ, et al. Sleep disordered breathing and mortality: eighteen-year follow-up of the Wisconsin sleep cohort. Sleep. 2008;31(8):1071-8.

16. Marshall NS, Wong KK, Cullen SR, Knuiman MW, Grunstein RR. Sleep apnea and 20-year follow-up for all-cause mortality, stroke, and Cancer incidence and mortality in the Busselton health study cohort. J Clin Sleep Med. 2014;10:355-62.

17. Punjabi NM, Caffo BS, Goodwin JL, Gottlieb DJ, Newman AB, O'Connor GT, et al. Sleep-disordered breathing and mortality: a prospective cohort study. PLoS Med. 2009;6(8):e1000132.

18. Marin JM, Agusti A, Villar I, Forner M, Nieto D, Carrizo SJ, Barbé F, Vicente E, Wei Y, Nieto FJ, Jelic S. Association between treated and untreated obstructive sleep apnea and risk of hypertension. JAMA. 2012;307:2169-76.

19. Hla KM, Young T, Hagen EW, Stein JH, Finn LA, Nieto FJ, et al. Coronary heart disease incidence in sleep disordered breathing: the Wisconsin sleep cohort study. Sleep. 2015;38:677-84

20. Gottlieb DJ, Yenokyan G, Newman AB, O'Connor GT, Punjabi NM, Quan SF, et al. Prospective study of obstructive sleep apnea and incident coronary heart disease and heart failure: the sleep heart health study. Circulation. 2010;122:352-60.

21. Reutrakul S, Mokhlesi B. Obstructive sleep apnea and diabetes: a state of the art review. Chest. 2017:152:1070-86.

22. Quan SF, Wright R, Baldwin CM, Kaemingk KL, Goodwin JL, Kuo TF, et al. Obstructive sleep apnea-hypopnea and neurocognitive functioning in the sleep heart health study. Sleep Med. 2006;7:498-507.

23. Terán-Santos J, Jiménez-Gómez A, Cordero-Guevara J. The association between sleep apnea and the risk of traffic accidents. Cooperative group Burgos-Santander. N Engl J Med. 1999;340:847-51.

24. Martínez-García MA, Campos-Rodriguez F, Durán-Cantolla J, de la Peña M, Masdeu MJ, González M, et al. Spanish sleep network. Obstructive sleep apnea is associated with cancer mortality in younger patients. Sleep Med. 2014;15:742-8.

25. Nieto FJ, Peppard PE, Young T, Finn L, Hla KM, Farré R. Sleep-disordered breathing and cancer mortality: results from the Wisconsin sleep cohort study. Am J Respir Crit Care Med. 2012;186:190-4.

26. Kushida CA, Nichols DA, Holmes TH, Quan SF, Walsh JK, Gottlieb DJ, et al. Effects of continuous positive airway pressure on neurocognitive function in obstructive sleep apnea patients: the apnea positive pressure long-term efficacy study (APPLES). Sleep. 2012;35:1593-602

27. Montserrat JM, Ferrer M, Hernandez L, Farré R, Vilagut G, Navajas D, et al. Effectiveness of CPAP treatment in daytime function in sleep apnea syndrome: a randomized controlled study with an optimized placebo. Am J Respir Crit Care Med. 2001:164:608-13.

28. Barnes M, McEvoy RD, Banks S, Tarquinio N, Murray CG, Vowles N, et al. Efficacy of positive airway pressure and oral appliance in mild to moderate obstructive sleep apnea. Am J Respir Crit Care Med. 2004;170: 656-64.

29. Caples SM, Rowley JA, Prinsell JR, Pallanch JF, Elamin MB, Katz SG, et al. Surgical modifications of the upper airway for obstructive sleep apnea in adults: a systematic review and meta-analysis. Sleep. 2010;33:1396-407.

30. Sarkhosh K, Switzer NJ, El-Hadi M, Birch DW, Shi X, Karmali S. The impact of bariatric surgery on obstructive sleep apnea: a systematic review. Obes Surg. 2013;23:414-23.

31. Chirinos JA, Gurubhagavatula I, Teff K, Rader DJ, Wadden TA, Townsend R, et al. CPAP, weight loss, or both for obstructive sleep apnea. N Engl J Med. 2014:370:2265-75.

32. Peppard PE, Young T, Palta M, Skatrud J. Prospective study of the association between sleep-disordered breathing and hypertension. N Engl J Med. 2000;342:1378-84. 
33. Mokhlesi B, Finn LA, Hagen EW, Young T, Hla KM, Van Cauter E, et al. Obstructive sleep apnea during REM sleep and hypertension. results of the Wisconsin Sleep Cohort. Am J Respir Crit Care Med. 2014;190:1158-67

34. Vgontzas AN, Li Y, He F, Fernandez-Mendoza J, Gaines J, Liao D, et al. Mildto-Moderate Sleep Apnea is associated with Incident Hypertension: Age Effect. Sleep. 2019:42:zsy265. https://doi.org/10.1093/sleep/zsy265.

35. Barbé F, Durán-Cantolla J, Sánchez-de-la-Torre M, Martínez-Alonso M, Carmona C, Barceló A, et al. Effect of continuous positive airway pressure on the incidence of hypertension and cardiovascular events in nonsleepy patients with obstructive sleep apnea: a randomized controlled trial. JAMA. 2012;307:2161-8

36. Montesi SB, Edwards BA, Malhotra A, Bakker JP. The effect of continuous positive airway pressure treatment on blood pressure: a systematic review and meta-analysis of randomized controlled trials. J Clin Sleep Med. 2012;8:587-96.

37. Loredo JS, Ancoli-Israel S, Dimsdale JE. Sleep quality and blood pressure dipping in obstructive sleep apnea. Am J Hypertens. 2001;14:887-92.

38. Stevens SL, Wood S, Koshiaris C, Law K, Glasziou P, Stevens RJ, et al. Blood pressure variability and cardiovascular disease: systematic review and metaanalysis. BMJ. 2016;354:14098

39. Calhoun DA, Jones D, Textor S, Goff DC, Murphy TP, Toto RD, et al. Resistant hypertension: diagnosis, evaluation, and treatment. A scientific statement from the American Heart Association professional education Committee of the Council for high blood pressure research. Hypertension. 2008;51:140319.

40. Logan AG, Perlikowski SM, Mente A, Tisler A, Tkacova R, Niroumand M, et al. High prevalence of unrecognized sleep apnoea in drug-resistant hypertension. J Hypertens. 2001;19:2271-7.

41. Martinez-Garcia MA, Capote F, Campos-Rodriguez F, Lloberes P, Díaz de Atauri MJ, Somoza M, et al. Effect of CPAP on blood pressure in patients with obstructive sleep apnea and resistant hypertension: the HIPARCO randomized clinical trial. JAMA. 2013;310:2407-15.

42. MacMahon S, Peto R, Cutler J, Collins R, Sorlie P, Neaton J, et al. Epidemiology: blood pressure, stroke, and coronary heart disease; Part 1, prolonged difference in blood pressure: prospective observational studies corrected for the regression dilution bias. Lancet. 1990;335:765-74.

43. Muraki I, Wada H, Tanigawa T. Sleep apnea and type 2 diabetes. J Diabetes Investig. 2018;9:991-7.

44. Kendzerska T, Gershon AS, Hawker G, Tomlinson G, Leung RS. Obstructive sleep apnea and incident diabetes. A historical cohort study. Am J Respir Crit Care Med. 2014;190:218-25.

45. Appleton SL, Vakulin A, McEvoy RD, Wittert GA, Martin SA, Grant JF, et al Nocturnal hypoxemia and severe obstructive sleep apnea are associated with incident type 2 diabetes in a population cohort of men. J Clin Sleep Med. 2015;11:609-14

46. Lui MM, Ip MS. Disorders of glucose metabolism in sleep-disordered breathing. Clin Chest Med. 2010;31:271-85.

47. Labarca G, Reyes T, Jorquera J, Dreyse J, Drake L. CPAP in patients with obstructive sleep apnea and type 2 diabetes mellitus: systematic review and meta-analysis. Clin Respir J. 2018;12:2361-8.

48. Barcelo A, Barbe F, de la Pena M, Martinez P, Soriano JB, Piérola J, et al. Insulin resistance and daytime sleepiness in patients with sleep apnea. Thorax. 2008;63:946-50.

49. Newman AB, Nieto FJ, Guidry U, Lind BK, Redline S, Pickering TG, et al. Sleep Heart Health Study Research Group Relation of sleep-disordered breathing to cardiovascular disease risk factors: The Sleep Heart Health Study. Am J Epidemiol. 2001;154:50-9.

50. Nadeem $R$, Singh M, Nida M, Kwon S, Sajid H, Witkowski J, et al. Effect of obstructive sleep apnea hypopnea syndrome on lipid profile: a metaregression analysis. J Clin Sleep Med. 2014;10:475-89.

51. Martínez-Cerón E, Barquiel B, Bezos AM, Casitas R, Galera R, García-Benito C, et al. Effect of continuous positive airway pressure on glycemic control in patients with obstructive sleep apnea and type 2 diabetes. A randomized clinical trial. Am J Respir Crit Care Med. 2016;194:476-85.

52. Campos-Rodriguez F, Gonzalez-Martinez M, Sanchez-Armengol A, JuradoGamez B, Cordero-Guevara J, Reyes-Nuñez N, et al. Effect of continuous positive airway pressure on blood pressure and metabolic profile in women with sleep apnoea. Eur Respir J. 2017;50:1700257. https://doi.org/10.1183/ 13993003.00257-2017

53. Somers VK, Javaheri S. Cardiovascular effect of sleep-related breathing disorders. In: Kryger M, Roth T, Dement WC, editors. Principles and practice of sleep medicine. 6th ed. Philadelphia: Elsevier; 2017. p. 1243-52.
54. Camacho M, Certal V, Brietzke SE, Holty JE, Guilleminault C, Capasso R. Tracheostomy as treatment for adult obstructive sleep apnea: a systematic review and meta-analysis. Laryngoscope. 2014;124:803-11.

55. McEvoy RD, Antic NA, Heeley E, Luo Y, Ou Q, Zhang X, SAVE investigators and coordinators. CPAP for prevention of cardiovascular events in obstructive sleep apnea. N Engl J Med. 2016;375:919-31.

56. Peker Y, Glantz H, Eulenburg C, Wegscheider K, Herlitz J, Thunström E. Effect of positive airway pressure on cardiovascular outcomes in coronary artery disease patients with nonsleepy obstructive sleep apnea. The RICCADSA randomized controlled trial. Am J Respir Crit Care Med. 2016;194:613-20.

57. Lloberes P, Duran J, Martinez-Garcia MA, Marin JM, Ferrer A, Corral J, et al. Diagnosis and treatment of sleep apnea-hypopnea syndrome. Arch Bronconeumol. 2011:47:143-56.

58. Société de Pneumologie de Langue Française; Société Française d'Anesthésie Réanimation; Société Française de Cardiologie; Société Française de Médecine du Travail; Société Française d'ORL; Société de Physiologie; Société Française de Recherche et de Médecine du Sommeil. Recommendations for clinical practice. Obstructive sleep apnea hypopnea syndrome in adults. Rev Mal Respir. 2010;27:806-33.

59. Qaseem A, Holty JE, Owens DK, Dallas P, Starkey M, Shekelle P, Clinical Guidelines Committee of the American College of Physicians. Management of obstructive sleep apnea in adults: a clinical practice guideline from the American College of Physicians. Ann Intern Med. 2013;159:471-83.

60. Eckert DJ, White DP, Jordan AS, Malhotra A, Wellman A. Defining phenotypic causes of obstructive sleep apnea. Identification of novel therapeutic targets. Am J Respir Crit Care Med. 2013;188:996-1004.

61. Tuomilehto HP, Seppa JM, Partinen MM, Peltonen M, Gylling H, Tuomilehto $\mathrm{JO}$, et al. Lifestyle intervention with weight reduction: first-line treatment in mild obstructive sleep apnea. Am J Respir Crit Care Med. 2009;179:320-7.

62. Foster GD, Borradaile KE, Sanders MH, Millman R, Zammit G, Newman AB, et al. Sleep AHEAD Research Group of Look AHEAD Research Group. A randomized study on the effect of weight loss on obstructive sleep apnea among obese patients with type 2 diabetes: the sleep AHEAD study. Arch Intern Med. 2009;169:1619-26.

63. Hudgel DW, Patel SR, Ahasic AM, Bartlett SJ, Bessesen DH, Coaker MA, et al. American Thoracic Society assembly on sleep and respiratory neurobiology. The role of weight management in the treatment of adult obstructive sleep apnea: an official American Thoracic Society clinical practice guideline. Am J Respir Crit Care Med. 2018;198:e70-87.

64. Billing ME, Krishnan V, Su G, Donovan LM, Patel SR, Hudgel DW, et al. Clinical practice guideline summary for clinicians: the role of weight Management in the Treatment of adult obstructive sleep apnea. Ann Am Thorac Soc. 2019;16:405-8

Ready to submit your research? Choose BMC and benefit from:

- fast, convenient online submission

- thorough peer review by experienced researchers in your field

- rapid publication on acceptance

- support for research data, including large and complex data types

- gold Open Access which fosters wider collaboration and increased citations

- maximum visibility for your research: over $100 \mathrm{M}$ website views per year

At $\mathrm{BMC}$, research is always in progress.

Learn more biomedcentral.com/submission 